\title{
Investigation of Selected Aspects of Fraction Understanding
}

\author{
Gabriela Pavlovičová, Lucia Vargová \\ Department of Mathematics, Constantine the Philosopher University in Nitra, \\ Tr. Andreja Hlinku 1, 94974 Nitra, Slovakia
}

\begin{abstract}
The paper focuses on the investigation of relations among perception of fraction as a measure and addition, equivalence, comparison of fractions. Arising from the previous studies, two research questions were stated. The first deals with the connection between location of the fraction on the number line and comparison and equivalence of fractions. The second deals with the connection between location of the fraction on the number line and addition of fractions. As a research tool, one part of the special developed fraction test connected to Sfard's theory of reification was used. For data analysing Statistical Implicative Analysis was used. Sample consisted of 930 learners at the age of 15 in Slovakia.
\end{abstract}

Keywords - mathematics education, fractions subconstructs, Statistical Implicative Analysis.

\section{Introduction}

Fractions are one of the most problematic areas in mathematics education in general. Many Slovak, Czech as well as foreign studies show this, which point to problems with understanding the term fraction. However, what is causing the poor understanding of fractions by learners remains questionable. Many authors have long been devoted to this issue.

DOI: $10.18421 /$ TEM92-37

https://doi.org/10.18421/TEM92-37

Corresponding author: Gabriela Pavlovičová, Department of Mathematics, Constantine the Philosopher University in Nitra, Tr. Andreja Hlinku 1,

94974 Nitra, Slovakia.

Email: gpavlovicova@ukf.sk

Received: 08 February 2020.

Revised: 01 May 2020.

Accepted: 06 May 2020.

Published: 27 May 2020.

(c))BY-NC-ND (C) 2020 Gabriela Pavlovičová \& Lucia Vargová; published by UIKTEN. This work is licensed under the Creative Commons AttributionNonCommercial-NoDerivs 4.0 License.

The article is published with Open Access at www.temjournal.com
For instance, Hejný et al. [1] are devoted to methodology of introducing fractions. They also describe the usage of three basic fractions models in addition and multiplicative operation on fractions. In [2] were investigated dependencies between cognitive-individual variable Personal need for Structure and solution of word problems connected to fractions. It was found that there is an inversely proportional relation between these two variables. Pantziara and Philippou [3] proposed special fraction test which indicates the influence of Sfard's theory of reification to teaching and learning fractions. Charalambous and Pita-Pantazi [4] confirmed that pupils achieve best results in tasks focused on fractions as a part of whole. They also confirmed that fraction, as a part of whole is a base for understanding to other fractions subconstructs. They also found out that operator subconstruct of fraction is connected with multiplicative operations on fractions. Hannula [5] found out that despite the fact that pupils in Finland are learning fractions for two years (from 5th to 7 th grade) the half of pupils from $7^{\text {th }}$ grade are not able to place the fraction on a number line.

In practice, however, we often encounter the fact that, despite the fact that pupils are familiar with the rules for counting fractions, they remain helpless in a task involving a non-standard situation. This means that knowledge is only stored as memory tracks without reference to the already established knowledge structure. Hejný et al. [6] states that apparently there was no development of learner's thinking and the idea of fraction. The knowledge the pupil has reached is verbal and formal [1].

Kieren [7] proposed four different interpretations of fractions that have certain relationship. $\mathrm{He}$ distinguishes fraction as a measure, ratio, quotient and operator. Further, he adds that in each fraction interpretation there is also appearing the elements of fraction as a part of the whole. That is why the part whole was subconstruct of fraction established as a fifth interpretation of fractions.

Fractions are one of the first problematic topics for learners. One of the problems can be that their understandings of fractions are often mechanical, and they depend on the representation of the fraction. The 
researches [8], [9] found out that for learners is more difficult to place a proper fraction on a number line than represents this fraction in a continuous or discrete model. They also found out, that learners are able to locate the fraction on the number line of length one, but they are not able to place this fraction on number line of length two. Finally, though able to form equivalents for a fraction, learners often do not mark the equivalent fractions (e.g. 1/3 and 2/6) as the same point on a number line.

Behr, et al. [10] found out, that students taught the common denominator method for comparing two fractions tend to ignore it, and focus on rules associated with ordering whole numbers. Students who correctly compare numerators if the denominators are equal often compare denominators if the numerators are equal.

According to [11], students who are learning computational algorithms involving fractions have difficulty connecting their concrete actions with manipulatives with their symbolic procedures. Often, a student's personal competence with a rote procedure "outstrips" his/her conceptual understanding of fractions; the unfortunate result is that students cannot monitor their work, or check their answers only by repeating the rote procedure, and they are unable to judge the reasonableness of their answer.

In the research [11] was shown that students in the tasks focused on fraction equivalence performed best on the area items and line segment items, worse on the set items, and the poorest on the number line items.

\section{Theoretical Basic for the Research}

A key study for the presented research is a book [12] in which, the issue of fractions and the individual forms of fraction perception are described in detail. Another important book on the area of fractions is [13]. Smith [14] suggests that learners are able to master measure interpretation of fractions when they master order and equivalence of fractions before. According to [15] to master the fraction addition operations learners first have to master measure interpretation of fractions. This statement is also supported by Kieren [7], although he adds that understanding fraction as a measure is the most difficult for pupils. He argues that for understanding the measure subconstruct of fractions, children need to master three following cognitive structures:

a) The first is the notion of a unit and its arbitrary division;

b) Second, a child has to be able to conceptualize part-whole relationships in this context and recognize equivalent settings arising from partitioning of the unit (for example $1 / 2=3 / 6$ etc.);

c) c) Third, the child has to develop the concept of an order relation.

Comparing fractions is methodologically more difficult than comparing natural numbers. It highlights the multifaceted notion of fraction and it also makes a proper conception for comparing quantitative characteristic of different range classes. In the school practice we often encounter with the fact, that pupil compare the fractions by the conversion of fraction to a decimal number or using learned rule - the cross product method:

$$
a b>c d \leftrightarrow a d>b c, \text { where } a, b, c, d>0[1] .
$$

One of the key understandings regarding comparison of fractions is the compensatory relation between the size and number of equal parts in partitioned unit. Children's attention needs to be drawn to the fact that the greater the number of parts into which the unit has been partitioned, the smaller the fraction size, and vice versa [16].

As students' understanding of fraction concept grows, they often move from ordering and comparing fractions and finding equivalent fractions to adding and subtracting fractions [14].

According to previous studies, two research questions were stated:

1. Is there any connection between measure subconstruct of fraction and comparison and equivalence of fractions?

2. Is there any connection between measure subconstruct of fraction and addition of fractions?

\section{Research Methodology}

Data were collected in July 2017. 930 learners of the 9th grade attending 35 elementary schools in Slovakia were involved in the research. The research was carried out at a time when learners had completed national testing of mathematical competencies which takes place annually in Slovakia called Testovanie 9 (translation Testing 9), and they also had completed secondary school entrance interviews. Learners were prepared for Testovanie 9 by repeating the whole curriculum of the secondary level of education. So, we can expect that these learners will have repeated, learned and memorized knowledge of fractions and rational numbers, and we should investigate the dependencies resulting from the research questions. The tasks were solved by learners in a single lesson in their classroom

As a research tool, part of the specially developed fraction test designed by Cypriot researchers Pantziara and Philippou was used. Test was designed in accordance with Sfard [17]. She proposed a three- 
stage model of knowledge acquisition, namely: an interiorization stage, a condensation stage and a reification stage.

Original fraction test contained 21 tasks, which were divided in seven groups (numbered 1,2..7) and in three columns (named A, B, C) representing the stage of knowledge acquisition by Sfard. In February and March 2016, the pre-research was realized. It was verified whether the test should be used in Slovak conditions. Based on the statistical results we can conclude that the fraction test is a sufficiently reliable tool and with the little correction, it could be used for research [18].

In our research, triads from 4 th to 7 th sets of tasks were used. Each task is classified according to the name, for example, the task B4 means that this task represents fourth row, and the second column which represents the condensation stage.

The fourth triad of tasks (A4, B4, C4) is focused on measure subconstruct of fractions. Learners should be able to place a number on a number line and also to determine the number from the number line.

The fifth triad of tasks (A5, B5, C5) is connected with equivalence of fractions. Learners should be able to use the procedure, to alternate between two models of fractions, and to solve a word problem that connects a symbolic representation of fraction with model of fraction.

The sixth triad of tasks (A6, B6, C6) is connected with comparison of fractions. Learners should be able to use algorithm for comparing two fractions with like denominator and also with unlike denominator, to know order, equivalence and density of fractions, to find a fraction between two fractions with consecutive denominators.

The seventh triad of tasks (A7, B7, C7) is connected with addition of fractions. Students should be able to apply the learned algorithm, to express fractions in the same quality, to understand a fraction as a single number, and to solve a word problems.

The method used for data analysis was Statistical Implicative Analysis (SIA). The SIA was created to build association rules. Therefore, we can use it to look for relationships between variables. For SIA analysis, the C.H.I.C (Classification Hiérarchique Implicative et Cohésitive) software was used. The C.H.I.C software generates two oriented graphs into form oriented hierarchical tree and an implication graph. It also generates non-oriented graph based on likelihood of the links named similarity tree [19].

The SIA method deals with answering the question: "If an object has a property, does it also have another one?". Even though the answer to this question is rarely true, we may notice that there is a trend among the properties of objects. The aim of SIA is to emphasize this trend in a set of the given properties [19]. In article the similarity index, cohesion index and implication intensity threshold were used to provide more detailed information in respect to stated research questions.

\section{Analysis and Discussion}

For giving answers to the research questions the SIA analysis was used. Fig. 1 and Fig. 2 represent graphs generated by software CHIC. The most significant connections are highlighted in red.

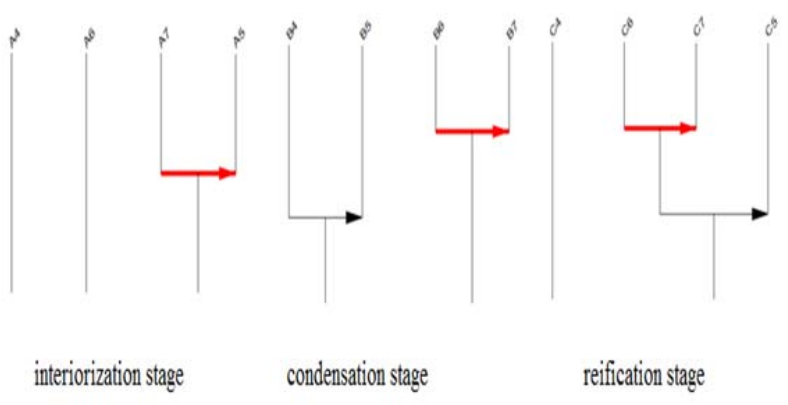

Figure 1. Hierarchy trees for each stage of Sfard's theory of reification

There is a hierarchy tree for each stage of Sfard's theory of reification in the Fig. 1. The implication $\mathrm{A} 7 \Rightarrow \mathrm{A} 5$ (Cohesion $=0.62$ ) is observed in the hierarchy tree in the interiorization stage. It means that if learners can add fractions with the same denominator, then they can add a numerator to the equality of two fractions so that the fractions are equivalent. From the statistically significant implication rule, based on the implication of $\mathrm{B} 6 \Rightarrow \mathrm{B} 7$ $($ Cohesion $=0.81)$ at the condensation stage it can be concluded, that if learners can compare two fractions with different denominators, then they can also add two fractions with different denominators, too. The implication $\mathrm{C} 6 \Rightarrow \mathrm{C} 7$ (Cohesion $=0.85$ ) at the reification stage suggests that if learners are able to solve the task of comparing fractions, then they can also solve the task of adding fractions.

The hierarchy tree in the Fig. 1 also shows the following implications $(\mathrm{C} 6 \Rightarrow \mathrm{C} 7) \Rightarrow \mathrm{C} 5$. In task $\mathrm{C} 6$, learners have to find a fraction that is larger than $1 / 7$ and smaller than 1/6. Learners solved this task in different ways. One way was to adjust to a common denominator as follows: $6 / 42<x<7 / 42$. Since there is no integer between the numbers 6 and 7 in the numerator, learners expanded the fractions by two and they were given: $12 / 84<\mathrm{x}<14 / 84$. Then they easily found a fraction of $13 / 84$. In task $C 7$, the learners had to solve a word task in which they were to add two fractions with different denominators. It was also an adjustment to the common denominator. In general, we can say that if learners are able to solve the task of comparing fractions, then they are able to solve the problem of addition of fractions, 
which implies that they are able to solve the problem of equivalence of fractions.

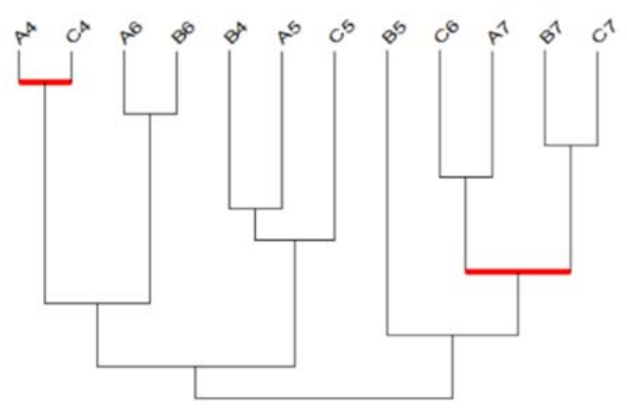

Figure 2. Similarity graph for all tasks

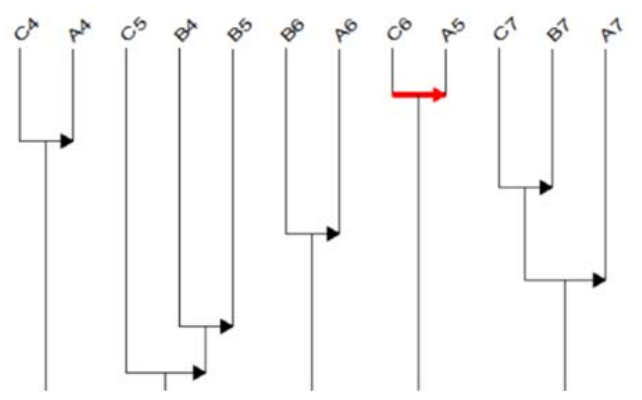

Figure 3. Hierarchy tree for all tasks

There is a similarity graph for all tasks in the test in the Fig. 2 and hierarchy tree for all tasks in the test in the Fig. 3. The similarity between tasks A4 and C4 (similarity $=0.98$ ) appears to be most significant. Both tasks are aimed at understanding the fraction as a measure. Task A4 represents the interiorization stage; task $\mathrm{C} 4$ represents the reification stage. The implication of $\mathrm{C} 4 \Rightarrow \mathrm{A} 4$ (Cohesion $=0.99)$ can be read from the hierarchical tree. It means that if a learner solves a task representing a fraction as a measure at the highest level of reification stage, then they solve a similar task at the interiorization stage.

Another similarity can be seen between tasks A6 and B6 (similarity $=0.97$ ). Both tasks are aimed at comparing fractions, wherein task A6 represents the interiorization stage and task B6 represents the condensation stage. Based on the implication $\mathrm{B} 6 \Rightarrow \mathrm{A} 6($ Cohesion $=0.93)$, it can be argued that if learners are able to solve a task at the condensation stage when comparing fractions, then they are able to solve a similar task at the interiorization stage.

Similarity can be seen in the solutions of tasks B4 and A5 (similarity $=0.95$ ) and among tasks B4, A5 and $\mathrm{C} 5$ (similarity $=0.88$ ). Each task represents a different stage in Sfard's theory of reification. Tasks A5 and C5 are aimed at monitoring the level of understanding the equivalence of fractions at the stage of interiorization and reification, task B5 is aimed at understanding the fraction as a measure at the condensation stage. The similarity in the solution of these tasks may have arisen due to the use of knowledge about the division of the whole into parts.
Similarity may also stem from the research [16], explaining the finding by which in order to understand the perception of a fraction as a measure, learners have to learn how to work with comparisons and equality of fractions first.

Another similarity is the similarity of tasks C6 and A7 (similarity $=0.97$ ), tasks B7 and C7 (similarity $=$ 0.97 There is a statistically significant similarity in tasks solutions ( similarity $=0.86$ ) between the groups C6, A7 and B7, C7. Task C6 is focused on ordering fractions at the reification stage, while tasks A7, B7, $\mathrm{C} 7$ are focused on addition of fractions at individual levels of Sfard's theory of reification. Based on the implication of $(\mathrm{C} 7 \Rightarrow \mathrm{B} 7) \Rightarrow \mathrm{A} 7$ (Cohesion $=0.79)$, it can be stated that if learners are able to solve the problem of addition of fractions at the stage of reification, then they are able also solve tasks at the condensation and interiorization stages.

A statistically significant implication rule shows the implication of $\mathrm{C} 6 \Rightarrow \mathrm{A} 5$ (Cohesion $=1)$. This means that if learners can solve the task of ordering fractions at the stage of reification, then they are able also solve the task of equivalence of fractions at the stage of interiorization. This implication appears to be based on the complexity of task C6. The extension of fractions is needed to solve the task A5. In task C6, we also need to expand the fractions to get the right result.

There is an implication graph for all items in the test which was generated by the software CHIC in the Fig.4. Implication intensity threshold is shown on the graph in different colors: blue (95), green (90), and grey (85).

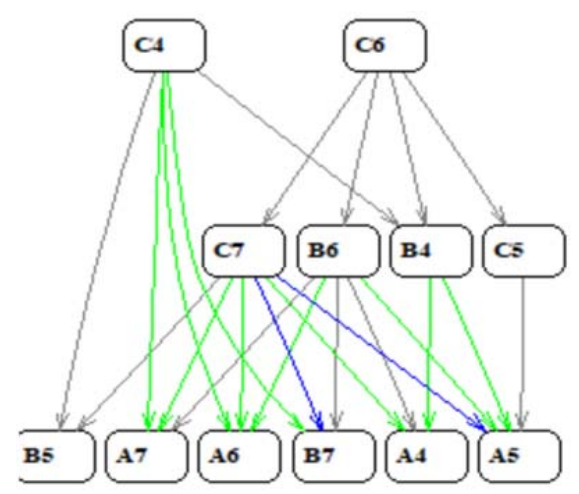

Figure 4. Implicative graph for all tasks in the test

The implicative graph was divided horizontally into three levels. At the highest level in the implicative graph are tasks C6 and C4. These tasks directly or vicariously imply other tasks mostly at the stage of interiorization or condensation. Tasks C6 and $\mathrm{C} 4$ are obviously the most difficult. In the middle of implicative graph are tasks C7, B6, B4 a C5. These tasks are little easier than the previous two tasks in terms of solution success, but they can also be considered as more complex because various 
implications are derived from them. At the lowest level are tasks A4, A5, A6, A7, B5, B7, which are the easiest in terms of success of the solutions, but also in terms of Sfard's theory of reification because all the implications are derived to them.

The implications $\mathrm{C} 4 \Rightarrow \mathrm{B} 4 \Rightarrow \mathrm{A} 4$ and $\mathrm{C} 6 \Rightarrow \mathrm{B} 6 \Rightarrow \mathrm{A} 6$ reflecting this theory. It means that if learners can solve the task at the reification stage then they can solve similar tasks at the stage of condensation and interiorization. Next, the implications $\mathrm{C} 4 \Rightarrow \mathrm{A} 7$ and $\mathrm{C} 4 \Rightarrow \mathrm{B} 7$ can be seen. It means that if learns can solve the task focused on the fractions as a measure at the stage of reification than they can solve the tasks focused on addition of fractions at the stage of condensation and reification.

These implications confirm the claim [10], where it is stated that understanding of measure personality of fractions is necessary to acquire proficiency in adding operations on fractions. Implications $\mathrm{C} 4 \Rightarrow \mathrm{B} 5$ and $C 4 \Rightarrow B 4 \Rightarrow A 5$ confirm that if learners can solve the task focused on understanding the fraction as a measure at the stage of reification then they can solve the tasks focused on fraction equivalence at the stage of condensation and interiorization. Interesting is the implication $\mathrm{C} 6 \Rightarrow \mathrm{B} 4 \Rightarrow \mathrm{A} 5$. It means that if learners can solve the task focused on ordering the fractions at the stage of reification then they also can solve the task focused on fractions as a measure at the stage of condensation. This implies that they can solve the task focused on fraction equivalence at the stage of interiorization.

These implications particularly confirmed the statement of the Smith [14], who expects to fully develop the measure personality of fractions learners one also need to master the order and equivalence of fractions.

The implications $\mathrm{C} 6 \Rightarrow \mathrm{C} 7 \Rightarrow \mathrm{B} 7$ and $\mathrm{C} 6 \Rightarrow \mathrm{C} 7 \Rightarrow \mathrm{A} 7$ means that if learners can solve the task focused on ordering the fractions, then they can solve the task focused on fraction addition, both at the stage of reification. This implies that they are able to solve the task focused on addition of fraction at the condensation and interiorization stages.

The implications $\mathrm{C} 6 \Rightarrow \mathrm{C} 7 \Rightarrow \mathrm{B} 5$ and $\mathrm{C} 6 \Rightarrow \mathrm{C} 7 \Rightarrow \mathrm{A} 5$ means that if learners can solve the task focused on ordering the fractions, then they can solve the task focused on addition of fraction, both at the reification stage. This implies that learners can solve the task focused on fraction equivalence at the stage of condensation and interiorization.

The implications $\mathrm{C} 6 \Rightarrow \mathrm{B} 6 \Rightarrow \mathrm{A} 7$ and $\mathrm{C} 6 \Rightarrow \mathrm{B} 6 \Rightarrow \mathrm{B} 7$ shows that if learners can solve the task focused on the fractions order at the stage of reification, then they can solve the task focused on ordering the fractions at the stage of condensation. This implies that they can solve the task focused on addition of fractions at the stage of condensation and reification.
The implication $\mathrm{C} 6 \Rightarrow \mathrm{B} 6 \Rightarrow \mathrm{A} 4$ means that if learners can solve the task focused on the fractions order at the stage of reification, then they can solve the task focused on ordering the fractions at the condensation stage. This implies that they can solve the task focused on fraction as a measure subconstruct at the stage of interiorization.

The implications $\mathrm{C} 6 \Rightarrow \mathrm{B} 4 \Rightarrow \mathrm{A} 4$ and $\mathrm{C} 6 \Rightarrow \mathrm{B} 4 \Rightarrow \mathrm{A} 5$ shows that if learners can solve the task focused on the fractions order at the stage of reification, then they can solve the task focused on fraction as a measure at the stage of condensation. This implies that they are able to solve the task focused on fraction addition at the interiorization stage, and also task focused on fraction equivalence at the stage of interiorization.

The implication $\mathrm{C} 6 \Rightarrow \mathrm{C} 5 \Rightarrow \mathrm{A} 5$ shows that if learners can solve the task focused on ordering the fractions, then they can solve the task focused on fraction equivalence, both at the stage of reification. This implies that they can solve the task focused on fraction equivalence at the stage of interiorization.

From the implication graph it can be seen that $\mathrm{C} 6$ is the most complex task because its correct solution leads to correct solution of all the others tasks except C4.

\section{Conclusion}

The Statistical Implicative Analysis was used in order to give answers to stated research questions. The similarity tree and hierarchical tree for each of Sfard's theory of reification stage were analyzed. All types of graphs, the implicative graph included, for all tasks in the test were analyzed, too.

The answer to the first research question, whether there is any connection between measure subconstruct of fraction and fractions comparison and equivalence, is positive. This connection exists for each stage of Sfard's theory. The similarity between solutions of individual tasks for each stage appeared. The implication between learner's correct solutions of the task focused on the measure subconstruct understanding and correct solutions of the task which is focused on the fractions equivalence appeared in the stage of condensation. This relation was confirmed also from the view of analysis of all tasks in the test.

The answer to the second research question, whether there is any connection between measure subconstruct of fraction and addition of fractions, is negative. This connection was not shown for any stage according to Sfard. This finding is in accordance with the study results [4] that the effect of the measure subconstruct on the additive operations of fractions was not statistically significant. This relationship remained an open question in their study. 
Another important finding is the confirmation of Sfard's theory of knowledge acquisition that can be read from the direction regarding the implications of individual graphs. It can be stated that the difficulty of individual tasks in the test is gradually increasing.

Further relations can be seen from the implicative graph (Fig. 4), which was constructed for all tasks in the test. The implicative graph shows several interesting findings.

Division of tasks into three stages is the first finding. All tasks except A5 and A6 copy the tasks distribution that was created according to percentage success rate of the individual tasks solutions.

The second finding is that these stages also copy Sfard's theory of reification. Implication relationships lead from the most difficult, most complex tasks gradually to less demanding, less complex to the easiest tasks.

The third finding is that the implication graph also shows some connection between the number line and the fraction addition. In particular, if learners are able to solve a task focused on understanding a fraction as a measure at the stage of reification, then they are able to solve tasks focused on addition of fractions at the stage of condensation and interiorization.

The fourth finding is the confirmation of a link between the ordering and addition of fractions and between equivalence and addition of fractions. The relationship between equivalence and addition of fractions is shown in the form of a statement: For learners who tend to understand addition of fractions, they have to be able to solve tasks focused on the equivalence of fractions first. Therefore, a new, unforeseen relationship has emerged.

No relationship between the measure subconstruct of fractions and addition of fractions in the Slovak schools' environment may stem from the content of the state educational program. The number line is not typical model in teaching fractions in Slovakia. The teaching addition of fractions is based on practicing algorithms more than modelling in Slovak mathematics education.

\section{Acknowledgements}

This paper was created with support of projects 1/0149/18 VEGA: Konceptualizácia pojmu zlomok vo vzt'ahu $k$ osobnej potrebe štruktúry (Conceptualization of Fractions in Relation to Personal Need for Structure).

\section{References}

[1]. Hejný, M. (1989). Teória vyučovania matematiky: diel 2. Slovenské pedagogické nakladatel'stvo.

[2]. Svecova, V., \& Pavlovicova, G. (2016). Screening the Personal Need for the Structure and solving word problems with fractions. SpringerPlus, 5(1), 652.
[3]. Pantziara, M., \& Philippou, G. (2011). Levels of students' "conceptions" of fractions. Educational Studies in Mathematics, 79, 61-83.

[4]. Charalambous, C. Y., \& Pitta-Pantazi, D. (2007). Drawing on a theoretical model to study students' understandings of fractions. Educational studies in mathematics, 64(3), 293.

[5]. Hannula, M. S. (2003). Locating Fraction on a Number Line. International Group for the Psychology of Mathematics Education, 3, 17-24.

[6]. Hejný, M., Novotná, J., \& Stehlíková, N. (2004). Dvacet pět kapitol z didaktiky matematiky, 1. díl. Praha: PedF UK.

[7]. Kieren, T. E. (1976, April). On the mathematical, cognitive and instructional. In Number and measurement. Papers from a research workshop (Vol. 7418491, p. 101).

[8]. Novillis, C. (1976). An Analysis of the Fraction Concept into a Hierarchy of Selected Subconcepts and the Testing of the Hierarchical Dependencies. Journal for Research in Mathematics Education, 7(3), 131-144.

[9]. Novillis, C. (1980). Seventh-Grade Students' Ability to Associate Proper Fractions with Points on the Number Line. In T. Kieren (Ed.), Recent Research on Number (pp. 125-150). Columbus, Ohio: Information Reference Center, Ohio State University.

[10].Behr, M. J., Wachsmuth, I., Post, T. R., \& Lesh, R. (1984). Order and equivalence of rational numbers: A clinical teaching experiment. Journal for research in mathematics education, 323-341.

[11]. Wearne, D., \& Hiebert, J. (1988). A cognitive approach to meaningful mathematics instruction: Testing a local theory using decimal numbers. Journal for research in mathematics education, 19, 371-384.

[12]. Lamon, S. J. (2013). MORE! Teaching Fractions and Ratios for Understanding: In-Depth Discussion and Reasoning Activities. Routledge.

[13]. Petit, M. M., Laird, R. E., Marsden, E. L., \& Ebby, C. B. (2015). A focus on fractions: Bringing research to the classroom. Routledge.

[14].Smith, J. P. (2002). The development of students' knowledge of fractions and ratios. In B. Litwiller, \& G. Bright (Eds.), Making Sense of Fractions, Ratios, and Proportions (pp. 3-17). Virginia: NCTM.

[15].Behr, M. J., Lesh, R., Post, T., \& Silver, E. A. (1983). Rational number concepts. Acquisition of mathematics concepts and processes, 91-126.

[16].English, L. D., \& Halford, G. S. (2012). Mathematics education: Models and processes. Routledge.

[17].Sfard, A. (1991). On the dual nature of mathematical conceptions: Reflections on processes and objects as different sides of the same coin. Educational studies in mathematics, 22(1), 1-36.

[18].Švecová, V., Pavlovičová, G., Rybanský, L. \& Klimentová, L. (2017). Reifikácia zlomkov vo vzt’ahu $k$ osobnej potrebe štruktúry. [The Reification of Fractions in Relation to the Personal Need of Structure]. Praha: Wolters Kluwer.

[19].Gras, R., Suzuki, E., Guillet, F., \& Spagnolo, F. (2008). Statistical Implicative Analysis, Theory and Applications. Springer. 